\title{
Anaphylactic Reaction to a Change in the Route of Administration of Abatacept: A Case Study
}

\author{
Kan Imai ${ }^{1,2,3 *}$, Daisaku Tokunaga1,2, Masashi Ishidaa,2 \\ ${ }^{1}$ Department of Orthopaedics, Kyoto Prefectural Rehabilitation Hospital for Mentally and Physically Disabled, Kyoto, Japan \\ ${ }^{2}$ Department of Orthopaedics, Graduate School of Medical Science, Kyoto Prefectural, University of Medicine, Kyoto, Japan \\ ${ }^{3}$ Department of Sports and Para-Sports Medicine, Graduate School of Medical Science, Kyoto Prefectural University of Medicine, \\ Kyoto, Japan \\ Email: ^kan-imai@koto.kpu-m.ac.jp
}

How to cite this paper: Imai, K., Tokunaga, D. and Ishida, M. (2020) Anaphylactic Reaction to a Change in the Route of Administration of Abatacept: A Case Study. Open Journal of Rheumatology and Autoimmune Diseases, 10, 64-69.

https://doi.org/10.4236/ojra.2020.102008

Received: March 23, 2020

Accepted: May 10, 2020

Published: May 13, 2020

Copyright (c) 2020 by author(s) and Scientific Research Publishing Inc. This work is licensed under the Creative Commons Attribution International License (CC BY 4.0).

http://creativecommons.org/licenses/by/4.0/

\begin{abstract}
The incidence of anaphylactic reaction after the long-term use of abatacept has not been reported until now. Herein, we present a case of rheumatoid arthritis (RA) in which the patient experienced an anaphylactic reaction one year after initiation of treatment with abatacept. A 75-year-old woman visited our hospital with symptoms of bilateral knee pain and swelling. She was initially treated with methotrexate $(6 \mathrm{mg} /$ week increased to $8 \mathrm{mg} /$ week). Two months later, because of inadequate response, self-injections of abatacept (subcutaneous; $125 \mathrm{mg}$ every two weeks) were prescribed. However, 6 months later, because of frequent stomatitis, the methotrexate dose was decreased to 6 $\mathrm{mg} /$ week, which resulted in worsening of RA. We changed the route of abatacept administration from subcutaneous injection to intravenous infusion (500 $\mathrm{mg} / \mathrm{month}$ as a drip). After $30 \mathrm{~min}$ of starting the drip, the patient experienced itchiness and drop in vital signs, which were managed using methylprednisolone ( 2 doses, $125 \mathrm{mg}$ each), dopamine hydrochloride $(8 \mathrm{mg} / \mathrm{h})$, and oxygen therapy (flow decreased from $3 \mathrm{~L} / \mathrm{min}$ to $1 \mathrm{~L} / \mathrm{min}$ ). Wheals and redness were treated with oral antihistamines. Six hours after the onset of the anaphylactic reaction, the vital signs were stabilized. On the subsequent day, the patient's general state was confirmed to be normal. One month later, etanercept $(25 \mathrm{mg})$ treatment was initiated. The patient is currently in remission. We recommend caution when changing the route of administration and dosage of abatacept in anti-cyclic citrullinated peptide antibody-positive patients or those with a history of mild infusion-related reaction.
\end{abstract}

\section{Keywords}

Rheumatoid Arthritis, Abatacept, Anaphylactic Reaction 


\section{Introduction}

Rheumatoid arthritis (RA) is a chronic inflammatory autoimmune disease. Early and appropriate intervention with conventional systemic disease-modifying antirheumatic drugs (csDMARDs), such as methotrexate (MTX) and biological DMARDs (bDMARDs), has made clinical, structural, and functional remission of RA possible [1]. However, respiratory complications, such as pneumonitis and tuberculosis are associated with the use of bDMARDs. In particular, the incidence of bDMARD-related respiratory complications is higher in patients aged $\geq 65$ years [2].

Abatacept, a bDMARD approved for use in Japan since 2010, is reported to be associated with fewer complications than other bDMARDs in elderly patients [2]. Anaphylactic shocks occurred in $0.12 \%$ patients who received abatacept, as an infusion-related reaction [3]; however, there have been no reports on the incidence of anaphylactic reaction as an adverse reaction to the long-term (one or more years) use of abatacept.

Herein, we report the case of anaphylactic reaction that occurred after switching from the subcutaneous (injection form) to intravenous route (infusion form) of administration.

\section{Case Presentation}

Informed consent was obtained from the patient for publication of the case and associated images.

A 74-year-old woman was diagnosed with bilateral gonarthrosis by a local physician, after she experienced subjective symptoms of bilateral knee pain and swelling; and received conservative therapy. She visited our hospital at age 75 years when the symptoms did not improve; she was diagnosed with RA based on the physical findings of bilateral swelling and pain and the findings of blood and serological tests (white blood cell [WBC] count: 8500/ $\mu$ l, C-reactive protein [CRP] level: $13.74 \mathrm{mg} / \mathrm{dl}$, anti-cyclic citrullinated peptide [anti-CCP] antibody level: $9.3 \mathrm{U} / \mathrm{ml}$, matrix metalloproteinase-3 [MMP-3] level: $284.5 \mathrm{ng} / \mathrm{ml}$ ). Before starting therapy, her clinical and simplified disease activity indices (CDAI and SDAI) were 17.2 and 30.9 , respectively.

Treatment was started at a dose of $6 \mathrm{mg} /$ week of MTX and increased to 8 $\mathrm{mg} /$ week. However, the response to this treatment was inadequate (CRP level: $2.9 \mathrm{mg} / \mathrm{dl}$, MMP-3 level: $202.0 \mathrm{ng} / \mathrm{ml}$, CDAI: 11.0, SDAI: 13.9); thus, two months after starting MTX therapy, she was administered $125 \mathrm{mg}$ abatacept subcutaneously every two weeks, which was deemed particularly appropriate considering her age. Symptoms, blood cell counts, and serological parameters improved: joint swelling, 0; joint pain, 0; WBC count, 5200/ $\mu$; and CRP level, $0.8 \mathrm{mg} / \mathrm{dl}$; she entered remission one month after starting treatment with abatacept (CDAI: 0, SDAI: 0.8). Six months after administering abatacept, she complained of frequent stomatitis; therefore, MTX dose was decreased to $6 \mathrm{mg} / \mathrm{week}$, but knee swelling and pain worsened bilaterally, and the swelling of the metacarpopha- 
langeal (MP) joint of the right middle finger worsened. Blood cell counts (WBC count: $4400 / \mu \mathrm{l}]$ and CRP levels $(0.6 \mathrm{mg} / \mathrm{dl})$ also increased; RA worsened to low disease activity state (CDAI: 8.3, SDAI: 8.9). This was deemed to be a result of poorly controlled RA because of the decrease in MTX dose. We considered prescribing a normal dosage of abatacept, that is, a weekly subcutaneous injection; however, 12 months after starting abatacept treatment (patient age, 76 years), the drug was administered in the form of intravenous infusion (500 mg/month) because the patient could not administer self-injections.

Before administration, her general state was confirmed to be normal (body temperature, $36.6^{\circ} \mathrm{C}$; blood pressure, $128 / 60 \mathrm{mmHg}$; heart rate, $68 \mathrm{bpm} ; \mathrm{SpO}_{2}$, $96 \%)$. Abatacept $500 \mathrm{mg}$ was administered through a drip over a period of 30 min. Subsequently (30 min after starting the drip), she developed itchiness all over her body; however, her vital signs remained normal (blood pressure, 128/60mmHg; heart rate, $68 \mathrm{bpm}$; $\left.\mathrm{SpO}_{2}, 94 \%\right)$. Therefore, she was observed on her bed.

Her state of consciousness decreased 35 min after starting the drip, and her vital signs dropped: blood pressure, 94/30 $\mathrm{mmHg}$; heart rate, $63 \mathrm{bpm}$; and $\mathrm{SpO}_{2}$, $87 \%$. Oxygen therapy at a flow rate of $3 \mathrm{~L} / \mathrm{min}$ was administered. An additional intravenous route was secured, and the saline drip was started. Two doses of 125 mg methylprednisolone (Solu-Medrol) were administered; the first dose was administered intravenously, while the second dose was added to $100 \mathrm{ml}$ saline solution and administered as a drip. Twenty-five minutes after the onset of the anaphylactic reaction (55 min after starting the drip), she became conscious; however, considering the state of her vital signs (blood pressure, $70 / 35 \mathrm{mmHg}$; heart rate, $72 \mathrm{bpm} ; \mathrm{SpO}_{2}, 90 \%$ ), treatment with $8 \mathrm{mg} / \mathrm{h}$ dopamine hydrochloride (CATABON Low) was initiated. Thirty-five minutes after the onset of anaphylactic reaction (65 min after starting the drip), her vital signs improved: blood pressure, 90/40mmHg; heart rate, $75 \mathrm{bpm} ; \mathrm{SpO}_{2}, 94 \%$. Because her blood pressure increased, dopamine hydrochloride treatment was discontinued.

Eighty minutes after the onset of anaphylactic reaction (110 min after starting the drip), she complained of symptoms of pharyngitis and had a flushed face, but her vital signs improved: blood pressure, 125/52mmHg; heart rate, $68 \mathrm{bpm}$; and $\mathrm{SpO}_{2}, 92 \%$. Therefore, she was transferred from the treatment room to the general ward.

Two hours after the onset of the anaphylactic reaction (2.5 hours after starting the drip), wheals and redness appeared all over the body; thus, the patient was treated by icing and administration of oral antihistamines. $\mathrm{SpO}_{2}$ increased to $100 \%$ with $3 \mathrm{~L} / \mathrm{min}$ oxygen therapy; therefore, the flow rate of oxygen was decreased to $1 \mathrm{~L} / \mathrm{min}$. Four hours and $45 \mathrm{~min}$ after the onset of the anaphylactic reaction (5 hours $15 \mathrm{~min}$ after starting the drip), the wheals improved to geographic rubefaction; however, the patient's blood pressure was elevated to $185 / 104 \mathrm{mmHg}$; thus, oral amlodipine $(2.5 \mathrm{mg})$ was administered. $\mathrm{SpO}_{2}$ remained at $100 \%$ with $1 \mathrm{~L} / \mathrm{min}$ oxygen therapy; therefore, oxygen supply was 
discontinued. Six hours after the onset of the anaphylactic reaction (6.5 hours after starting the drip), vital signs were stable: blood pressure, $130 / 80 \mathrm{mmHg}$; heart rate, $72 \mathrm{bpm}$; and $\mathrm{SpO}_{2}, 95 \%$; therefore, the drip was discontinued. Seven hours after the onset of the anaphylactic reaction ( 7 hours 30 min after starting the drip), rubefaction of the body disappeared. The next day, we confirmed no issues in the general state. Blood tests also indicated no marked liver or kidney abnormalities (WBC count: 9400/ $\mu$, aspartate aminotransferase [AST] level: 18 $\mathrm{IU} / \mathrm{l}$, alanine transaminase [ALT] level: $20 \mathrm{IU} / \mathrm{l}$, blood urine nitrogen [BUN] level: $18.3 \mathrm{mg} / \mathrm{dl}$, creatinine [Cre] level: $0.57 \mathrm{mg} / \mathrm{dl}$, CRP level: $2.15 \mathrm{mg} / \mathrm{dl}$ ); therefore, the patient was discharged.

Etanercept $25 \mathrm{mg}$ was injected subcutaneously for RA one month after administering an abatacept drip. There have been no side effects six months after starting etanercept (0 swollen or painful joints, WBC count: 3900/ $\mu$ l, CRP level: $0.2 \mathrm{mg} / \mathrm{dl}$, MMP-3 level: $42.3 \mathrm{ng} / \mathrm{ml}$ ), and currently, RA is in remission (CDAI: 0, SDAI: 0.2).

\section{Discussion}

Abatacept binds to CD80/CD86 on the antigen-presenting cell surface and blocks costimulatory signals mediated through the CD28-CD80/86 pathway to prevent T-cell activation and cytokine production involved in the onset of RA. It is a bDMARD that inhibits the production of inflammatory mediators and matrix metalloproteinases associated with the activation of other immune cells and joint connective tissue cells [4].

There are several previous reports on infections, chest pain, and gastrointestinal disorders that occur as serious adverse events after abatacept use [4] [5]. Salmon et al. studied serious infusion-related reactions in patients with RA who were administered biologics. They reported that serious anaphylactic reaction occurred in 1 of 827 patients 8 months after the administration of abatacept. Two of 1470 have had severe serious anaphylactic reactions to tocilizumab, an immunosuppressive drug used to treat RA, 2 and 4 months after starting its administration. However, there were no reports on serious anaphylactic reactions that occurred more than 1 year after its administration [3]. The risk of infusion-related reactions increases in anti-CCP antibody positive patients who have never been administered csDMARDs. They reported that serious symptoms were observed in approximately $25 \%$ of patients who have a history of mild infusion-related reactions.

Because the route of administration was changed from subcutaneous (injection) to intravenous (infusion), we compared the additives of abatacept in the two forms. Substances contained in intravenous drip preparations but not contained in subcutaneous preparations are maltose hydrate, sodium chloride, hydrochloric acid, and sodium hydroxide; there were no additives that could cause an anaphylactic reaction.

Muller et al. surveyed adverse reactions by switching the route of administra- 
tion of abatacept formulation from subcutaneous (injection) to intravenous route (drip preparation). They found serious adverse reactions in 4 of 49 patients within 6 months of changing the route of administration, but none were anaphylactic reactions [6].

The present case involved an anti-CCP antibody-positive patient who experienced a mild infusion-related stomatitis, while receiving subcutaneous abatacept injection; thus, this patient was at risk of a serious infusion-related reaction. Changes in the route of administration and increases in doses should be made with caution to minimize the risk of anaphylactic reactions, even if the administered drug is unchanged.

\section{Conclusion}

We report the case of anaphylactic reaction that occurred after switching from subcutaneous (injection form) to intravenous route (infusion form). We recommend caution when changing the route of administration and dosage of abatacept in anti-CCP antibody-positive patients who experience mild infusion-related reaction.

\section{Acknowledgements}

We would like to thank Editage [http://www.editage.com] for editing and reviewing this manuscript for English language.

\section{Conflicts of Interest}

The authors declare no conflicts of interest regarding the publication of this paper.

\section{References}

[1] Maini, R., St Clair, E.W., Breedveld, F., Furst, D., Kalden, J., Weisman, M., Smolen, J., Emery, P., Harriman, G., Feldmann, M. and Lipsky, P. (1999) Infliximab (Chimeric Anti-Tumour Necrosis Factor Alpha Monoclonal Antibody) versus Placebo in Rheumatoid Arthritis Patients Receiving Concomitant Methotrexate: A Randomised Phase III Trial. ATTRACT Study Group. Lancet, 354, 1932-1939. https://doi.org/10.1016/S0140-6736(99)05246-0

[2] Sekiguchi, M., Fujii, T., Matsui, K., Murakami, K., Morita, S., Ohmura, K., Kawahito, Y., Nishimoto, N., Mimori, T., Sano, H. and ABROAD Study Investigators (2016) Differences in Predictive Factors for Sustained Clinical Remission with Abatacept between Younger and Elderly Patients with Biologic-Naive Rheumatoid Arthritis: Results from the ABROAD Study. The Journal of Rheumatology, 43, 1974-1983. https://doi.org/10.3899/jrheum.160051

[3] Salmon, J.H., Perotin, J.M., Morel, J., Dramé, M., Cantagrel, A., Ziegler, L.E., Ravaud, P., Sibilia, J., Pane, I., Mariette, X., Gottenberg, J.E. and French Society of Rheumatology (2018) Serious Infusion-Related Reaction after Rituximab, Abatacept and Tocilizumab in Rheumatoid Arthritis: Prospective Registry Data. Rheumatology (Oxford), 57, 134-139. https://doi.org/10.1093/rheumatology/kex403

[4] Kremer, J.M., Dougados, M., Emery, P., Durez, P., Sibilia, J., Shergy, W., Steinfeld, S., Tindall, E., Becker, J.C., Li. T., Nuamah, I.F., Aranda, R. and Moreland, L.W. 
(2005) Treatment of Rheumatoid Arthritis with the Selective Costimulation Modulator Abatacept: Twelve-Month Results of a Phase iib, Double-Blind, Randomized, Placebo-Controlled Trial. Arthritis \& Rheumatology, 52, 2263-2271.

https://doi.org/10.1002/art.21201

[5] Westhovens, R., Kremer, J.M., Moreland, L.W., Emery, P., Russell, A.S., Li, T., Aranda, R., Becker, J.C., Qi, K. and Dougados, M. (2009) Safety and Efficacy of the Selective Costimulation Modulator Abatacept in Patients with Rheumatoid Arthritis Receiving Background Methotrexate: A 5-Year Extended Phase IIB Study. The Journal of Rheumatology, 36, 736-742. https://doi.org/10.3899/jrheum.080813

[6] Mueller, R.B., Gengenbacher, M., Richter, S., Dudler, J., Möller, B. and von Kempis, J. (2016) Change from Subcutaneous to Intravenous Abatacept and back in Patients with Rheumatoid Arthritis as Simulation of a Vacation: A Prospective Phase IV, Open-Label Trial (A-BREAK). Arthritis Research \& Therapy, 18, 88.

https://doi.org/10.1186/s13075-016-0985-2 